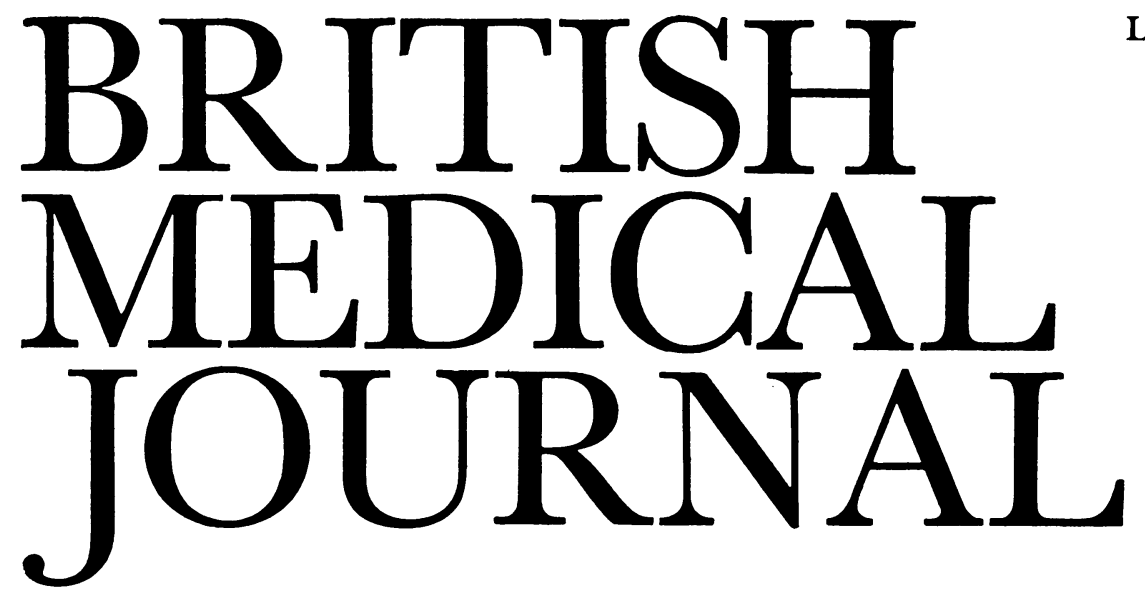

LONDON, SATURDAY 17 DECEMBER 1983

\title{
Alcoholic liver disease in the 1980s
}

Alcoholic liver disease is now firmly established as one of the main causes of illness and death in many industrial countries. In some cases the problem has become immense; alcoholic liver disease is now the second most common cause of death in men aged 25-44 in New York State. ${ }^{1}$ Though in a few countries such as France the death rate seems to have reached a plateau, in most (including Britain) the indications are that its incidence will continue to increase as it has done steadily over the past 20 years. ${ }^{23}$

This appalling trend is entirely predictable given the lack of a coherent national strategy on alcoholism. Perhaps the newly formed organisation Action on Alcohol Abuse, which at its launching in September emphasised the need for the development of effective preventive strategies, will be the vanguard of a new attack on the problem. At least the emergence of alcoholic liver disease as a major health problem world wide has focused attention on the need for more effective treatment and for a greater understanding of its clinical course and pathogenesis.

Several studies from both specialist and non-specialist units in Britain have given comprehensive accounts of the clinical features and clinical course of alcoholic liver disease. ${ }^{3-7}$ The most recent and largest of these is a multicentre survey undertaken by the Caledonian Society of Gastroenterology. ${ }^{7}$ A total of 510 patients with histologically documented alcoholic liver disease were identified from the eight centres in Scotland and Northern England participating in the study. In this series, which is probably representative of clinical practice in Britain, $40 \%$ of patients had cirrhosis at presentation. This proportion is lower than in earlier series-for example, the $57 \%$ in a survey from the Royal Free Hospital in the $1960 \mathrm{~s},{ }^{8} 60 \%$ from the same unit in $1975,{ }^{4}$ and $63 \%$ from King's College Hospital in 1967-75. ${ }^{5}$ To some extent this may reflect differences in referral practices, though fewer than $30 \%$ of patients admitted to the same department in the Royal Free Hospital since 1978 have cirrhosis (M Y Morgan, personal communication). It looks as if greater attempts are being made nowadays to detect alcoholic liver disease at an early stage. Furthermore, more patients with cirrhosis are still in the "compensated" stage in contrast to the experience reported from Birmingham, where throughout a 20 year period over two thirds of patients presented with ascites, liver failure, or variceal bleeding. ${ }^{3}$

One of the main difficulties in diagnosing alcoholic liver disease is eliciting a reliable history of alcohol intake. This holds true particularly for women, who initially tend to conceal their drinking habits. ${ }^{4}$ The diagnosis of alcoholic cirrhosis is in general easier: features such as ascites, jaundice, or haemorrhage should immediately point to the possibility of chronic liver disease. As the Caledonian Society study has pointed out, however, precirrhotic liver disease comes in a variety of guises. ${ }^{7}$ Jaundice and right hypochondrial pain are useful pointers to the diagnosis but occur in only a quarter of the patients. The most common symptoms are non-specific gastrointestinal disturbances such as nausea and vomiting $(40 \%)$, abdominal pain, and diarrhoea. Often, however, these reflect alcohol dependence or concomitant gastritis or peptic ulceration. A raised serum $\gamma$-glutamyltransferase activity is the most common laboratory abnormality in patients with alcoholic liver disease but does not reliably distinguish patients with cirrhosis from those with fatty liver only. Techniques such as grey scale ultrasonography and computer assisted tomography are being evaluated, ${ }^{9}$ but liver biopsy remains essential for the precise morphological diagnosis.

The past five years have seen a re-evaluation of many of the accepted concepts of the evolution of alcoholic liver disease. There is increasing evidence that alcoholic hepatitis is not an obligatory precursor of cirrhosis. Indeed, in its florid form, characterised by extensive necrosis and inflammation, alcoholic hepatitis is rare outside specialist units. Studies from North America ${ }^{10}$ and Japan ${ }^{11}$ provide evidence that an insidious fibrotic process may be the more usual pathway to cirrhosis. Nakano and colleagues have shown that patients with fibrosis around the terminal hepatic venules ("perivenular fibrosis") but with no signs of acute alcoholic hepatitis are likely to progress to cirrhosis if they continue drinking. ${ }^{10}$

The mechanisms by which alcohol initiates liver damage are still the subject of debate. The fatty liver arises, at least in part, from production of hydrogen equivalents and the reduced form of nicotinamide adenine dinucleotide, which fuel the reactions concerned in the synthesis of fats. The basis for the ballooning changes and necrosis remains uncertain. The toxic metabolite of alcohol, acetaldehyde, has been implicated, and raised plasma concentrations of acetaldehyde in patients with alcoholic liver disease have been related to subnormal activities of hepatic aldehyde dehydrogenase. ${ }^{12}$ Indeed, it has been suggested that a deficiency of a cytosolic component of this enzyme may be a primary defect in alco- 
holics, which predisposes them to develop dependence as well as a variety of physical complications. ${ }^{13}$ There is no evidence, however, that a genetic difference in the composition of aldehyde dehydrogenase, or of alcohol dehydrogenase, is responsible for differences in individual susceptibility to alcoholic hepatitis or cirrhosis. ${ }^{14}$ Whether these lesions develop solely as a result of the direct toxic effects of alcohol or its metabolites, ${ }^{15}$ or by way of immunological mechanisms, is still being argued. In animals fed on alcohol, myofibroblasts-cells which synthesise collagen-have been shown to proliferate in the absence of an inflammatory reaction. ${ }^{16}$ Resumption of drinking by patients with liver disease is followed by an increase in serum concentrations of procollagen peptideswhich are released during the synthesis of collagen. ${ }^{1718}$ Lymphocyte mediated cytotoxic reactions occur in alcoholic hepatitis, ${ }^{19}$ though such reactions have never been shown to be other than epiphenomena. Recent research has shown, however, that alcohol or acetaldehyde may render the liver cell membrane antigenic, thereby triggering an antibody dependent cytotoxic reaction ${ }^{20}$ or complement activation ${ }^{21}$; this work provides some insight into how immunological processes may play a more fundamental part in causing liver damage.

Genetic markers of susceptibility to alcoholic liver disease are still being sought, but it seems increasingly unlikely that there is a distinct group of people whose genetic make up predestines them to develop cirrhosis if they drink excessively. What genetic factors seem to do is to increase or decrease the likelihood of liver disease developing at a given alcohol intake. Women develop alcoholic liver disease more rapidly and at a lower daily alcohol intake than men. ${ }^{35}$ The most extensively investigated group of genetic markers are the HLA antigens. Associations have been described between several of these, including HLA-B8 and B40, and alcoholic hepatitis and cirrhosis, ${ }^{22-24}$ and an accelerated course to cirrhosis was seen in patients with HLA-B8. ${ }^{25}$ There is no one HLA antigen, however, that is uniformly associated with predisposition to alcoholic liver disease. ${ }^{26} 27$ This may indicate that a genetic marker of susceptibility is associated with different HLA antigens in different populations. It remains to be seen whether these markers will provide a practical way of detecting patients prone to develop cirrhosis.

The effective management of alcoholic liver disease continues to present difficulties. For upwards of 30 years most discussions have been prefaced by a statement that "the mainstays of treatment remain abstinence from alcohol and a nutritious diet." Is there really nothing more to it than that ? Certainly there have been advances in the treatment of certain complications of cirrhosis. The use of injection sclerotherapy has given a new confidence to those dealing with variceal haemorrhage. ${ }^{28}$ Treatment of ascites by aldosterone antagonists is more effective and less hazardous than the use of thiazides or frusemide alone. Yet paracentesis, which was abandoned long ago by most physicians for the treatment of ascites in patients with cirrhosis, is being re-evaluated: the preliminary results of a trial of this compared with treatment with diuretics (J Rodes, European Association for the Study of the Liver, Southampton, 1983) showed no difference in effectiveness or morbidity between the two approaches.

What are the prospects for a more fundamental attack on alcoholic liver disease? Since the disappointing results of the trials of corticosteroids in alcoholic hepatitis ${ }^{29}$ and the conflicting results of controlled trials of the antithyroid drug propylthiouracil,,$^{30} 31$ emphasis has shifted towards developing drugs which ameliorate the early biochemical abnormalities in- duced by alcohol metabolism. These so called "hepatoprotective drugs" have a wide array of actions including restoration to normal of the altered ratio of reduced to oxidised nicotinamide adenine dinucleotide that occurs as a result of alcohol metabolism, free radical scavenging properties, and membrane stabilising effects. Some of these drugs seem blessed with all these useful attributes. Though used extensively on the European mainland for "mal du foie" and similar national afflictions, they have not been introduced into clinical practice in Britain or North America. Moreover, recent controlled clinical trials of two of these drugs- $(+)$-cyanidanol-3 and thioctic acid-have not shown any effect on recovery from or prevention of liver damage.$^{32-34}$ If any of these drugs proved to be successful difficult ethical considerations would be raised about its place in treatment, for such a drug would be unlikely to protect against all the physical consequences of heavy drinking, and its use might well lead to exacerbation of the patient's dependence on alcohol because of the lack of a constraining influence on continued drinking.

More treatment programmes are being designed to promote abstinence, and at least here we are spared the debate about abstinence versus controlled drinking, for abstinence from alcohol is mandatory in patients with alcoholic hepatitis or cirrhosis. $^{32935}$ But how is it best achieved ? Surprisingly few trials of treatment for alcoholism have looked specifically at this group of patients with alcohol problems. Patients with alcoholic liver disease are less severely dependent on alcohol than those who attend alcoholism clinics, ${ }^{36}$ and they have a much more regular style of drinking than the intermittent and often explosive drinking of these other patients. Coexisting psychiatric illnesses, ${ }^{37}$ however, such as affective disorders, are found quite commonly, and this may partly explain why only a minority of patients maintain abstinence after discharge from hospital. ${ }^{335}$

In the absence of specific pharmacological treatments for alcoholic liver disease we can at least organise our services so that patients are assessed by a psychiatrist as well as the medical team. In a limited number of general hospitals multidisciplinary teams consisting of physicians, psychiatrists, and psychologists have been established, and even in these days of staff redundancies in the Health Service such an approach must surely be encouraged.

J B SAUNDERS

Lecturer in Liver Diseases,

Liver Unit,

King's College Hospital Medical School,

London SE5 8RX

${ }^{1}$ Bureau of Health Statistics and Analysis. New York City: summary of vital statistics 1980. New York: Department of Health, Bureau of Health Statistics and Analysis, 1981.

2 Office of Population Censuses and Surveys. Mortality statistics: cause. Review of the Registrar General on deaths by cause, sex, and age, in England and Wales, 1981. London: HMSO, 1983. (Series DH2 No 8.)

${ }^{3}$ Saunders JB, Walters JRF, Davies P, Paton A. A 20 -year prospective study of cirrhosis. Br Med f $1981 ; 282: 263-6$.

4 Morgan MY, Sherlock S. Sex-related differences among 100 patients with alcoholic liver disease. Br Med F 1977; : :939-41.

${ }^{5}$ Krasner N, Davis M, Portmann B, Williams R. Changing pattern of alcoholic liver disease in Great Britain: relation to sex and signs of autoimmunity. Br Med 7 1977; i:1497-500.

${ }^{6}$ Levi AJ, Chalmers DM. Recognition of alcoholic liver disease in a district general hospital. Gut 1978;19:521-5.

Hislop WS, Bouchier IAD, Allen JG, et al. Alcoholic liver disease in Scotland and north eastern England: presenting features in 510 patients. $Q \mathcal{F}$ Med $1983 ; 52: 232-43$.

${ }^{8}$ Brunt PW, Kew MC, Scheuer PJ, Sherlock S. Studies in alcoholic liver disease in Britain. I. Clinical and pathological patterns related to natural history. Gut 1974;15:52-8.

${ }^{9}$ Bydder GM, Kreel L, Chapman RWG, Harry D, Sherlock S, Bassar L. Accuracy of computed tomography in diagnosis of fatty liver. $\mathrm{Br} \mathrm{Med} \mathcal{F}$ $1980 ; 281: 1042$. 
${ }^{10}$ Nakano M, Worner TM, Lieber CS. Perivenular fibrosis in alcoholic liver injury: ultrastructure and histologic progression. Gastroenterology $1982 ; 83: 777-85$.

${ }^{11}$ Minato Y, Hasumura Y, Takeuchi J. The role of fat-storing cells in Disse space fibrogenesis in alcoholic liver disease. Hepatology 1983;3:559-66.

12 Palmer KR, Jenkins WJ. Impaired acetaldehyde oxidation in alcoholics. Gut $1982 ; 23: 729-33$.

13 Thomas M, Halsall BS, Peters TJ. Role of hepatic acetaldehyde dehydrogenase activity in alcoholism: demonstration of persistent reduction of cytosolic activity in abstaining patients. Lancet 1982;ii :1057-9.

${ }^{14}$ Ricciardi BR, Saunders JB, Williams R, Hopkinson DA. Hepatic ADH and ALDH isoenzymes in different racial groups and in chronic alcoholism. Pharmacol Biochem Behav 1983;18,suppl 1:61-5.

${ }^{15}$ Lewis KO, Paton A. Could superoxide cause cirrhosis ? Lancet 1982 ;ii : 188-9.

${ }^{16}$ Nakano M, Lieber CS. Ultrastructure of initial stages of perivenular fibrosis in alcohol-fed baboons. Am F Pathol 1982;106:145-55.

17 Niemela O, Risteli L, Sotaniemi EA, Risteli J. Aminoterminal propeptide of type III procollagen in serum in alcoholic liver disease. Gastroenterology $1983 ; 85: 254-9$.

${ }^{18}$ Hahn EG, Schuppan D. Collagen metabolism in liver disease. $n$ : BianchiI L, Gerok W, Landmann L, Sickinger K, Stalder GA, eds. Liver in metabolic diseases. Lancaster: MTP Press, 1983:309-23.

${ }^{19}$ Actis G, Mieli-Vergani G, Portmann B, Eddleston ALWF, Davis M, Williams R. Lymphocyte cytotoxicity to autologous hepatocytes in alcoholic liver disease. Liver 1983;3:8-12.

${ }^{20}$ Neuberger J, Crossley IR, Saunders JB, et al. Antibodies to alcoholaltered liver cell determinants in patients with alcoholic liver disease. Gut (in press).

${ }^{21}$ Barry RE. The pathogenesis of hepatitis in alcohol abuse and jejunoileal bypass. Lancet 1983; ;i :489-90.

22 Bell H, Nordhagen R. HLA antigens in alcoholics, with special reference to alcoholic cirrhosis. Scand 7 Gastroenterol $1980 ; 15: 453-6$.

${ }^{23}$ Morgan MY, Ross MGR, Ng CM, Adams DM, Thomas HC, Sherlock S, HLA-B8, immunoglobulins and antibody responses in alcohol-related liver disease. $f$ Clin Pathol $1980 ; 33: 488-92$.

${ }^{24}$ Eddleston ALWF, Davis $M$. Histocompatibility antigens in alcoholic liver disease. Br Med Bull 1982;38:13-6.
${ }^{25}$ Saunders JB, Wodak AD, Haines A, et al. Accelerated development of alcoholic cirrhosis in patients with HLA-B8. Lancet $1982 ; \mathrm{i}: 1381-4$.

${ }^{26}$ Rada RT, Knodell RG, Troup GM, Kellner R, Hermanson SM, Richards $M$. HLA antigen frequencies in cirrhotic and noncirrhotic male alcoholics: a controlled study. Alcoholism (NY) $1981 ; 5: 188-91$.

${ }^{27}$ Faizallah R, Woodrow JC, Krasner NK, Walker RJ, Morris AI. Are HLA antigens important in the development of alcohol-induced liver disease? $\mathrm{Br}$ Med f 1982;285:533-4.

${ }^{28}$ Macdougall BRD, Westaby D, Theodossi A, Dawson JL, Williams R. Increased long-term survival in variceal haemorrhage using injection sclerotherapy. Results of a controlled trial. Lancet $1982 ; \mathrm{i}: 124-7$.

${ }^{29}$ Sherlock S. Current problems in alcoholic liver disease. Alcohol and Alcoholism 1983;18:99-118.

${ }^{30}$ Orrego $\mathrm{H}$, Kalant $\mathrm{H}$, Israel $\mathrm{Y}$, et al. Effect of short-term therapy with propylthiouracil in patients with alcoholic liver disease. Gastroenterology $1979 ; 76: 105-15$.

${ }^{31}$ Hallé P, Paré P, Kaptein E, Kanel G, Redeker AG, Reynolds TB. Doubleblind, controlled trial of propylthiouracil in patients with severe acute alcoholic hepatitis. Gastroenterology 1982;82:925-31.

32 Colman JC, Morgan MY, Scheuer PJ, Sherlock S. Treatment of alcoholrelated liver disease with $(+)$-cyanidanol-3: a randomised double-blind trial. Gut 1980;21:965-9.

${ }^{33}$ World MJ, Aps EJ, Shaw GK, Thomson AD. (+)-Cyanidanol-3 for alcoholic liver disease: results of a six-month clinical trial. Alcohol and Alcoholism (in press)

${ }^{34}$ Marshall AW, Graul RS, Morgan MY, Sherlock S. Treatment of alcoholrelated liver disease with thioctic acid: a six month randomised doubleblind trial. Gut 1982;23:1088-93.

${ }^{35}$ Powell WJ Jr, Klatskin G. Duration of survival in patients with Laennec's cirrhosis. Influence of alcohol withdrawal, and possible effects of recent changes in general management of the disease. Am F Med 1968; 44:406-20.

${ }^{36}$ Wodak AD, Saunders JB, Ewusi-Mensah I, Davis M, Williams R. Severity of alcohol dependence in patients with alcoholic liver disease. Br Med F 1983;287:1420-2.

${ }^{37}$ Ewusi-Mensah I, Saunders JB, Wodak AD, Murray RM, Williams R. Psychiatric morbidity in patients with alcoholic liver disease. $\mathrm{Br} \mathrm{Med} \mathcal{J}$ $1983 ; 287$ : $1417-9$.

\section{Risks from radioiodine treatment of thyrotoxicosis}

British conservatism applies just as much to medicine as to anything else, and our use of radioiodine in thyroid disease has scarcely altered over the past 30 years. The time has surely come, however, to re-evaluate its risks in comparison with the alternatives. Radioiodine is suspect on three grounds: the possibilities of carcinogenesis and leukaemogenesis, genetic damage, and fetal damage.

These risks may be assessed in two ways. The first is by follow up of patients treated with radioiodine. Two very large studies have been published: 59000 patients were assessed by Pochin $^{1}$ and 36000 by Saenger et al from the cooperative North American study. ${ }^{2}$ Neither series found any excess of thyroid cancer, leukaemia, or cancer in general-indeed, there were fewer than expected cases of thyroid cancer, but the follow up period is probably still too short to support this.

The second approach is to attempt to calculate the risks as in the reports by the United Nations Scientific Committee on the Effects of Atomic Radiation. ${ }^{3}{ }^{4}$ All risks are then related to dose with conservative estimates of dosage from typical treatments with iodine-131-say, $7 \mathrm{mCi}$ or $0.25 \mathrm{GBq}$. The dose to gonad and bone marrow and the whole body dose may then be taken as about 5 and 10 rads (or cGy) respectively. ${ }^{5} 6$ The risks can then be calculated. For carcinogenesis the risks of all fatal cancer may be taken as about $10^{-4} / \mathrm{rad}$ and will therefore be about $10^{-3}$. This will be a lifetime risk with a latent period of perhaps 25 years. The risk of leukaemia will be about $2 \times 10^{-5} /$ rad and therefore only $2 \times 10^{-4}$. The chances of fatal thyroid cancer would be about $10^{-5} / \mathrm{rad}$ or about one in 10 for a radiation dose of 10000 rads. If this were correct excess cases must have been reported by now. In fact, publications world wide to 1981 contain only 26 cases, ${ }^{7}$ while there are now likely to be considerably more than one million patient years' experience. The explanation of the low risk is the very considerable reduction in the number of thyroid cells at risk: the same pattern is evident in the dose response relation seen in many animals, such as myeloid leukaemia ${ }^{8}$ and lung tumours ${ }^{9}$ in RF mice, where there is an initial rise in the incidence of the neoplasm as the dose of radiation is increased, then a peak or plateau, and, finally, a decline of incidence with higher doses.

The genetic risks are much more difficult to understand and express (at any rate, for a non-geneticist readership). The simplest way seems to be consideration of the dose which will double the "spontaneous" mutation risk, and a conservative estimate of this is about 100 rads. A typical radioiodine treatment dose will therefore increase the risk by about $5 \%$. The cause of many genetic diseases is multifactorial and any increase would be seen only after radiation of a whole population over several generations. In an individual there might be only about 20 dominant effects per million per rad of irradiation in men and a much lower risk in women. These figures should be compared with the spontaneous mutation rates for diseases such as achondroplasia and retinoblastoma, both about one in $10 .^{5}$ Furthermore, genetic risks will obviously be irrelevant unless the patient fathers or conceives a child.

The fetal risks are potentially much more serious, a significant chance of developmental abnormality coming from doses as low as 5 rads, especially in the first three months of pregnancy. The fetal thyroid does not concentrate iodine before about 12 